Выполнение домашнего задания по физической культуре студентами для повышения уровня фризических качеств

Лешкевич С.А. ${ }^{a}$, Лешкевич В.А. ${ }^{b}$, Липовая Н.Н. ${ }^{c}$, Потёмкина Е.И. ${ }^{d}$, Каргина С.Ю. ФГАОУ ВО «Севастопольский государственный университет»,

Севастополь, Российская Федерация.

a iD ORCID: https://orcid.org/0000-0001-7330-0483, e-mail: coach_basket@mail.ru

biD ORCID: https://orcid.org/0000-0002-8168-6643, e-mail: leshkevich75@mail.ru

ORCID: https://orcid.org/0000-0003-4726-5551, e-mail: natniksevastopol@mail.ru

diD ORCID: https://orcid.org/0000-0003-0449-9163, e-mail: lena.potyomkina@rambler.ru

e (iD ORCID: https://orcid.org/0000-0003-2919-0074, e-mail: cargina.su@mail.ru
DOI 10.31483/r-74515

УДК 37.012 .85

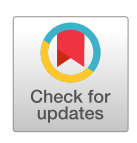

Резюме: В статье рассматривается вопрос о необходимости выполнения домашнего задания по предмету физической культуры для студентов в виде дополнительной нагрузки. Изучается проблема отсутствия двигательной активности и выполняется поиск решения в виде подборки определенных упражнений для того, чтобы приучить обучающегося к регулярным нагрузкам. Рассматриваются положительные и отрицательные стороны данного нововведения. Методы исследования. Для подтверждения теоретического предположения о пользе выполнения домашнего задания было проведено исследование, в котором участвовали две группы студентов, продолжительностью три месяца. В исследовании приняли участие 60 студентов (30 юношей и 30 девушек) в возрасте 17-19 лет, в котором их разделили поровну по половым признакам на 2 группы - контрольную (КГ) и экспериментальную (ЭГ). Результаты исследования. В результате тестирования, через 3 месяца выполнения домашнего задания, произошли улучшения физических качеств в экспериментальной группе, а именно улучшились такие показатели, как сила, выносливость, гибкость, ловкость, быстрота и координация движений. Делается вывод, что благодаря физическим упражнениям, выполняемым самостоятельно в домашних условиях, улучшается кровоснабжение мышц и регуляция их деятельности нервной системой - происходит рост мышечной массы, укрепляется иммунитет и, следовательно, улучшается самочувствие, в организме вырабатываются эндорфины, поэтому после тренировки студенты чувствуют себя лучше. Также тренировка мышечной системы повышает выносливость в условиях как физических, так и умственных нагрузок, благодаря активному образу жизни скорость обмена веществ в организме дольше остаётся на высоком уровне, что предотвращает старение. Регулярные занятия спортом облегчают засыпание и улучшают качество сна.

Ключевые слова: студенты, физическая культура, фризические упражнения, домашнее задание, регулярные нагрузки, повышение фризических качеств.

Для цитирования: Лешкевич С.А. Выполнение домашнего задания по физической культуре студентами для повышения уровня фризических качеств / С.А. Лешкевич, В.А. Лешкевич, Н.Н. Липовая [и др.] // Развитие образования. - 2020. - № 1 (7). - С. 55-58. DOI:10.31483/r-74515.

\title{
Performing Homework on Physical Education by Students to Increase the Level of Physical Qualities
}

\author{
Sergey A. Leshkevicha, Vadim A. Leshkevich ${ }^{b}$, Nataliya N. Lipovayac, \\ Elena I. Potyomkinad, Svetlana Yu. Kargina ${ }^{e}$ \\ FSAEI of HE "Sevastopol State University", \\ Sevastopol, Russian Federation. \\ ORCID: https://orcid.org/0000-0001-7330-0483, e-mail: coach_basket@mail.ru \\ iD ORCID: https://orcid.org/0000-0002-8168-6643, e-mail: leshkevich75@mail.ru \\ DORCID: https://orcid.org/0000-0003-4726-5551, e-mail: natniksevastopol@mail.ru \\ diD ORCID: https://orcid.org/0000-0003-0449-9163, e-mail: lena.potyomkina@rambler.ru \\ e iD ORCID: https://orcid.org/0000-0003-2919-0074, e-mail: cargina.su@mail.ru
}

\begin{abstract}
The question on the need to perform homework on physical education for students in the form of additional physical activity is considered in the article. The problem of motor activity lack is studied and a solution presented in the form of certain exercises set in order to accustom the student to regular physical activity is found. The positive and negative aspects of this innovation are considered. Method of research. To confirm the theoretical assumption about the benefits of doing homework, a study that lasted for three months was conducted. The study engaged 60 students (30 young males and 30 young females) aged 17-19 years, in which they were divided equally by gender into 2 groups - control (CG) and experimental (EG). The results of the study. As a result of experiment, after doing homework for 3 months, improvements in student's physical qualities in the experimental group could be observed. Among them: strength, endurance, flexibility, dexterity, speed and coordination of movements. It is concluded that due to physical exercises performed independently at home, the blood supply to the muscles and regulation of their activity by the nervous system improves - muscle mass increases, the immune system strengthens and, consequently, health improves, endorphins are produced in the body, so students feel better after training. Also, training the muscular system increases endurance in conditions of both physical and mental stress, thanks to an active lifestyle, the body's metabolic rate remains at a high level for long time, which prevents aging. Regular exercise makes it easier to fall asleep and improves the quality of sleep.
\end{abstract}

Keywords: students, physical exercises, physical education, homework, regular physical activity, improving physical qualities.

For citation: Sergey A. Leshkevich, Vadim A. Leshkevich, Nataliya N. Lipovaya, Elena I. Potyomkina, \& Svetlana Yu. Kargina (2020). Performing Homework on Physical Education by Students to Increase the Level of Physical Qualities. Razvitie obrazovaniya = Development of education, 1(7), 55-58. (In Russ.) DOI:10.31483/r-74515. 


\title{
Физкультурӑпа киле панӑ е̌с̧е студентсем вӑй-хал пахалӑхӗн шайне ӳстерме туни
}

\author{
Лешкевич С.А. ${ }^{a}$, Лешкевич В.А. ${ }^{\text {, }}$ Липовая Н.Н. ${ }^{\text {, }}$ Потёмкина Е.И. ${ }^{\text {, }}$ Каргина С.Ю. \\ АВ ФПА «Севастополь патшалӑх университечӗ» ВУ, \\ Севастополь, Рас̧с̧ей Патшалӑхе̌. \\ a iD ORCID: https://orcid.org/0000-0001-7330-0483, e-mail: coach basket@mail.ru \\ b(iD ORCID: https://orcid.org/0000-0002-8168-6643, e-mail: leshkevich75@mail.ru \\ ORCID: https://orcid.org/0000-0003-4726-5551, e-mail: natniksevastopol@mail.ru \\ d'iD ORCID: https://orcid.org/0000-0003-0449-9163, e-mail: lena.potyomkina@rambler.ru \\ e(iD ORCID: https://orcid.org/0000-0003-2919-0074, e-mail: cargina.su@mail.ru
}

Аннотаци: Статьяра студентсем фрикультура предмечӗпе киле панӑ ӗс̧е хушма тиев вырӑнне тума тивӗс̧ пуррине ӗнентернӗ. Хускану активлӑхӗ с̧уккипе с̧ыхӑннӑ ыйтӑва тӗпченӗ, ӑна тивӗс̧терекен хурав тесе организма ялан ӗс̧леттерекен хӑнахтару комплексӗ сӗннӗ. С̧ак с̧ӗнӗлӗхӗн лайӑх тата начар енӗсене кӑтартнӑ. Киле панӑ ӗс̧е тунин усси пур текен теорие с̧иреплетме студентсен икӗ ушкӗнӗпе вис̧ уйӑх хушши тӗпчев ирттернӗ. Тӗпчеве 17 - 19 с̧ул тултарнӑ 60 студент хутшӑнчӗ (йӗкӗтсем - 30-ӑн, хӗрсем - 30-ӑн). Тӗрӗслев тата эксперимент ушкӑнӗсене тан хисеплӗ турӑмӑр. 3 уйӑх хыс̧с̆ӑн студентсем тест ыйтӑвӗсене хуравларӗс. Тестировани эксперимент ушкӑнӗнче ӗс̧ленӗ студентсен сывлӑхӗнче лайӑх улшӑну пулса иртнине кӑтартрӗ. Уйрӑммӑн илсен улшӑну ак мӗнре палӑрчӗ: вӑйра, хевтере, пис̧ӗлӗхре, вӑр-варлӑхра, хӑвӑртлӑхра, хускану килӗшўлӗхӗнче. Пӗтӗмлетў тунӑ: килте харпӑр хӑй тунӑ хӑнӑхтарусене пула мышцӑн юн с̧аврӑнӑшӗ лайӑхланать, ун ӗс̧не нерва системи лайӑхрах тӗрӗслесе тӑма тытӑнать - мышца масси ӱсет, имммунитет с̧ирӗпленет, апла тӑк кӑмӑл-туйӑм лайӑхланать, организм эндорфрин туса кӑларать. С̧авӑнпа тренировка хыс̧с̧ӑн студентсем организм лайӑх пулнине туяс̧с̧ӗ. Мышца системине тренировка пани чӑтӑмлӑха хул-сурӑма с̧ес̧ мар, ӑс-тӑна тиев парсан та пысӑклатать. Йӗркеллӗ пурӑнсан организмра веществосен улшӑнӑве̌ унчченхи пекех суўллӗ шайра юлать, с̧авӑнпа ватӑлӑва чарса тӑрать. Спорт занятийӗсене пӗр тӑтӑш хутшӑнни хӑвӑрт с̧ывӑрса кайма май парать, ыйхӑ пахалӑхне ӳстерет.

Tӗп сӑмахсем: вӑй-хал культури, студентсем, вӑй-хал хӑнӑхтарӑвӗсем, киле панӑ ӗс̧, пӗр тӑтӑш тиев (нагрузка) илни, вӑй-хал пахалӑхӗ ӱсни.

Цитатӑлама: Лешкевич С.А. Физкультурӑпа киле панӑ ӗс̧е студентсем вӑй-хал пахалӑхӗн шайне ӳстерме туни / С.А. Лешкевич, В.А. Лешкевич, Н.Н. Липовая [и др.] // Вӗренў аталанӑвӗ. - 2020. - № 1 (7). - С. 55-58. DOI:10.31483/r-74515.

\section{Введение}

$\mathrm{E}$ жедневно студенты подвергаются стрессам и информационным перегрузкам. Малая физическая активность снижает их работоспособность, повышает уровень заболеваемости. Слабая физическая подготовка снижает потенциал жизнеспособности студента [1].

На сегодняшний день довольно актуален вопрос о необходимости дополнительной регулярной физической нагрузки в виде выполнения домашнего задания студентами для развития физических качеств.

Некоторые студенты считают, что это нецелесообразно, так как у них просто не будет хватать времени на другие аспекты молодежного движения, помимо учебы. Давайте рассмотрим этот вопрос более подробно, так сказать, «обе стороны медали».

Современный студент действительно не может распределять свободное время и часто не успевает одновременно совмещать образовательную сферу с развитием физических качеств. К тому же проверка домашнего задания может быть затруднена спецификой предмета. Следует понимать, что обучающийся может просто игнорировать данное нововведение.

Теперь, что касается положительной стороны: во-первых, задание по физической культуре вряд ли будет громоздким и непонятным. Поэтому студент сможет при желании выделить 10-15 мин для выполнения нескольких упражнений. Во-вторых, проверить результативность и полезность данного новшества будет не так уж и сложно, достаточно просто провести тестирование до начала эксперимента и после, при этом ведется дневник самоконтроля, где будут записаны упражнения, дозировка, показатели ЧСС до нагрузки и после, самочувствие. В-третьих, за каждое дело требуется вознаграждение. В нашем случае в качестве вознаграждения прекрасно могут выступать оценки, которые мотивируют студента к выполнению упражнений. К тому же регулярное выполнение и соблюдение всех правил, которые были предложены преподавателем, развивает не только физические качества, но и психологические личностные: стремление быть лучшим, взаимопомощь, силу воли, целеустремленность и т. д.

В процессе исследования данного вопроса нами был поставлен ряд вопросов:

1. Какие упражнения можно выделять для самоподготовки в домашних условиях, находясь без присмотра тренера, которые не наносят вред здоровью?

2. Какие более полезные упражнения, а какие менее травмоопасные?

3. Какой их смысл, если выполнение может быть без соблюдения определенной техники, и к каким результатам они приведут?

Разберем для начала практическую часть, более приближенную к предмету. Во-первых, обязательно первой в очередности выполнения должна быть разминка, для каждого нового домашнего задания ее движения должны меняться. Во-вторых, для домашнего задания необходимо давать только те упражнения, которые были хорошо разучены на занятии по физической культуре, так как закрепить правильную технику без контроля со стороны преподавателя невозможно. В-третьих, домашнее задание не должно быть большим по объему и не следует переутомлять студента, чтобы не пропало желание для выполнения в дальнейшем комплекса упражнений. 
Из теории физического воспитания и культуры можно предложить студентам дополнительное задание в виде реферата, поиска интересных фактов, подготовки биографии известных спортсменов, описания различных видов техники движения, подвижных игр, презентации и многого другого [2].

Домашнее задание может быть также индивидуальным, здесь все зависит от преподавателя и показателей здоровья студента. При примерном выполнении всех предложенных вариантов улучшения своих физических качеств студент сможет улучшить свои показатели, уделив внимание слабым сторонам подготовки [3].

Meтоды. В качестве экспериментальной проверки комплекса домашних упражнений было проведено тестирование, в котором участвовали 60 студентов (30 юношей и 30 девушек) в возрасте 17-19 лет. Рецензентов разделили поровну по половым признакам на 2 группы - контрольную (КГ) и экспериментальную (ЭГ). Контрольная группа занималась только на занятиях по физической культуре в спортивном зале университета, а для экспериментальной группы было предложено выполнение комплекса упражнений для совершенствования двигательных качеств в домашних условиях. Также обязательным условием была видеосъёмка занятия и ведение дневника самоконтроля, где отражались показатели пульса до и после выполнения упражнений, дозировка и время выполнения. Дополнительный контроль над экспериментом вели преподаватели кафедры путем просмотра видеосъёмки и корректировки правильного выполнения техники комплекса упражнений. Занятия проводились 3 раза в неделю по расписанию, в те дни, когда нет занятий по физкультуре.

Комплекс упражнений был распределен на 3 тренировочных дня:

Понедельник:

Начало: 17:00 ч., окончание 17:30 ч.

Разминка: общеразвивающие упражнения (на все группы мышц) -5 мин.

1. Гладкий бег на спортивной площадке - 10 мин.

2. Подтягивания на перекладине (юноши по принципу «лестница» с увеличением количества раз), девочки - сгибание и разгибание рук в упоре от скамейки 10-15 раз.

3. Упражнение «Планка с упором на локти» - от 30 сек. с увеличением на каждой тренировке на 5 сек.
4. В висе на перекладине подъем прямых ног (юноши), согнутых в коленях (девушки) - 10-15 раз.

Вторник:

Начало: 17:00 ч., окончание 17:30 ч.

Разминка: общеразвивающие упражнения (на все группы мышц) - 5 мин.

1. Бег на короткую дистанцию 3 х 30 м.

2. Для развития силы: приседания - 3 х 20 раз (каждую тренировку прибавить 1 раз).

3. Прыжки на скакалке - 3 х 100 раз (каждую тренировку прибавить 5 раз).

4. Наклон туловища, стоя с фиксацией рук 5 сек. за пятки (5-8 раз).

Пятница:

Начало: 17:00 ч., окончание 17:30 ч.

Разминка: общеразвивающие упражнения (на все группы мышц) - 5 мин.

1. Челночный бег 4 × 10 м (3-5 раз).

2. Прыжки в длину (8-10 раз).

3. Продольный и поперечный шпагат с фиксацией 5 сек. (3-5 раз).

4. Медленный бег 10 мин.

Суббота:

Ходьба в парке или поход по пересеченной местности (6-8 км).

Во время эксперимента студентам предлагалось выполнение правил здорового питания:

1. Выпивать стакан воды за 15 минут перед каждым приемом пищи (норма воды за день 1,5-2 л зимой и 2-3 л летом).

2. Калорийную пищу употреблять только до 12 часов дня.

3. Все гарниры из рациона заменить только на овощные блюда.

4. Запрещено употребление сосисок, колбас, чипсов, сухариков, газированной воды, это вредит как фигуре, так и здоровью.

5. Кушать небольшими порциями каждые 2,5-3 часа.

6. Последний прием пищи за 3-4 часа до сна.

7. Один раз в неделю делать разгрузочный день (овощи, фрукты, зеленый чай).

8. Не запивать пищу водой и не пить воду в течение 40 минут после приема пищи.

Результаты исследования. До и после эксперимента провели тестирование по физическим качествам в группах. Предложили выполнение упражнения на

Таблица 1

Показатели результатов юношей и девушек до и после эксперимента в контрольной и экспериментальной группах

Table 1

Outcome measures of young male and young female before and after experiment in control and experimental groups

\begin{tabular}{|c|c|c|c|c|c|}
\hline \multirow{2}{*}{ Упражнение } & \multirow{2}{*}{ Пол } & \multicolumn{2}{|c|}{ Контрольная группа } & \multicolumn{2}{|c|}{ Экспериментальная группа } \\
\hline & & До & После & До & После \\
\hline Подтягивание на перекладине (кол-во раз) & ю & 7 & 8 & 7 & 10 \\
\hline Сгибание и разгибание рук в упоре лежа (кол-во раз) & д & 5 & 7 & 6 & 10 \\
\hline \multirow[t]{2}{*}{ Прыжки на скакалке (кол-во раз) } & ю & 103 & 110 & 98 & 122 \\
\hline & д & 112 & 119 & 113 & 132 \\
\hline \multirow[t]{2}{*}{ Наклон туловища вперед (см) } & ю & +7 & +7 & +6 & +10 \\
\hline & д & +10 & +10 & +9 & +13 \\
\hline
\end{tabular}


силу - подтягивание на перекладине (юноши) и сгибание и разгибание рук в упоре лежа для девушек, тест на выносливость - прыжки на скакалке за 1 мин. и на гибкость юноши и девушки выполняли тест - наклон вперед из положения стоя на скамейке. По результатам тестов до и после эксперимента получили средние данные 2-х групп (табл. 1).

В результате тестирования, через 3 месяца выполнения домашнего задания, произошло улучшение физических качеств в экспериментальной группе, а именно: возросла сила у юношей на 14\%, у девушек на 16\%, повысилась выносливость у юношей на $12 \%$, у девушек на $11 \%$, у юношей и девушек улучшилась гибкость на 14\%, а также значительно улучшились такие характеристики, как ловкость, быстрота и координация движений.

$B b l в o д b l$. По итогам эксперимента можно сказать об эффективности внедрения выполнения домашнего задания юношами и девушками по физическому воспитанию для улучшения физических качеств. Даже после завершения исследования эффективности внедрения дополнительных упражнений $45 \%$ юношей и $40 \%$ девушек продолжили самостоятельно заниматься. Это свидетельствует о том, что мышцы привыкли к нагрузкам, требуют каждодневной двигательной активности и происходит адаптация организма к нагрузкам. Улучшаются обменные процессы в мышцах, связках и сухожилиях, что защищает от повреждений суставы, кости и другие звенья опорно-двигательного аппарата. Также после выполнения необходимой нормы физических упражнений, как правило, повышается самооценка, регулируется вес (при соблюдении дополнительно правил рационального питания) и появляется стремление быть первым, быть лучшим.

\section{Список литературы}

1. Барчуков И.С. Физическая культура / И.С. Барчуков. - М.: Academia, 2017. - 304 с.

2. Виленский М.Я. Физическая культура и здоровый образ жизни студента (для бакалавров) / М.Я. Виленский, А.Г. Горшков. - М.: КноРус, 2018. - 256 с.

3. Гришина Ю.И. Физическая культура студента: учебное пособие / Ю.И. Гришина. - Ростов н/Д: Феникс, 2019. - 283 c.

\section{References}

1. Barchukov, I. S. (2017). Fizicheskaia kul'tura. M.: Academia.

2. Vilenskii, M. Ia., \& Gorshkov, A. G. (2018). Fizicheskaia kul'tura i zdorovyi obraz zhizni studenta (dlia bakalavrov). M.: KnoRus.

3. Grishina, Iu. I. (2019). Fizicheskaia kul'tura studenta: uchebnoe posobie. Rostov n/D: Feniks.

Информация об авторах Лешкевич Сергей Анатольевич старший преподаватель кафедры «Физвоспитание и спорт» ФГАОУ ВО «Севастопольский государственный университет», Севастополь, Российская Федерация.

Лешкевич Вадим Анатольевич старший преподаватель кафедры «Физвоспитание и спорт» ФГАОУ ВО «Севастопольский государственный университет», Севастополь, Российская Федерация.

Липовая Наталия Николаевна старший преподаватель кафедры «Физвоспитание и спорт» ФГАОУ ВО «Севастопольский государственный университет» Севастополь, Российская Федерация.

Потёмкина Елена Ивановна старший преподаватель кафедры «Физвоспитание и спорт» ФГАОУ ВО «Севастопольский государственный университет» Севастополь, Российская Федерация.

Каргина Светлана Юрьевна старший преподаватель кафедры «Физвоспитание и спорт» ФГАОУ ВО «Севастопольский государственный университет» Севастополь, Российская Федерация.
Information about the authors Sergey A. Leshkevich - senior lecturer of Physical Education and Sports Department, FSAEI of HE "Sevastopol State University", Sevastopol, Russian Federation.

Vadim A. Leshkevich - senior lecturer of Physical Education and Sports Department, FSAEI of HE "Sevastopol State University", Sevastopol, Russian Federation.

Nataliya N. Lipovaya - senior lecturer of Physical Education and Sports Department, FSAEI of HE "Sevastopol State University", Sevastopol, Russian Federation.

Elena I. Potyomkina - senior lecturer of Physical Education and Sports Department, FSAEI of HE "Sevastopol State University", Sevastopol, Russian Federation.

Svetlana Yu. Kargina - senior lecturer of Physical Education and Sports Department, FSAEI of HE "Sevastopol State University", Sevastopol, Russian Federation.
Авторсем суинчен пӗлтерни Лешкевич Сергей Анатольевич АВ ФПА «Севастополь патшалӑх университече̌» $\mathrm{B}{ }_{\mathrm{H}}$ «Физвоспитанипе спорт» кафедрин аслӑ преподавателе̌, Севастополь, Рас̧с̧ей Патшалӑхе̌.

\section{Лешкевич Вадим Анатольевич -} АВ ФПА «Севастополь патшалӑх университечӗ» $\mathrm{BУ}_{\mathrm{H}}$ «Физвоспитанипе спорт» кафедрин аслӑ преподавателё, Севастополь, Рас̧с̧ей Патшалӑхе̌.

\section{Липовая Наталья Николаевна -} АВ ФПА «Севастополь патшалӑх университечё» $\mathrm{BУ}$ «Физвоспитанипе спорт» кафедрин аслӑ преподавателӗ, Севастополь, Рас̧с̧ей Патшалӑхе̌.

\section{Потёмкина Елена Ивановна -}

АВ ФПА «Севастополь патшалӑх университече̌» $\mathrm{BУ}_{\mathrm{H}}$ «Физвоспитанипе спорт» кафедрин аслӑ преподавателё, Севастополь, Рас̧с̧ей Патшалӑхе̌.

\section{Каргина Светлана Юрьевна -} АВ ФПА «Севастополь патшалӑх университечӗ» $\mathrm{BУ}$ «Физвоспитанипе спорт» кафедрин аслӑ преподавателӗ, Севастополь, Рас̧с̧ей Патшалӑхе̌. 